\title{
Electronic structure, anisotropic elastic and thermal properties of monoclinic $\mathrm{Ca}_{2} \mathrm{Nb}_{2} \mathrm{O}_{7}$
}

\author{
Jun Yang ${ }^{1}$, Meng zhao ${ }^{1}$, Muhammad shahid ${ }^{1}$, Jing Feng ${ }^{2}$, Chunlei Wan ${ }^{1}$, Wei Pan $^{1 *}$
}

1. State Key Laboratory of New Ceramics and Fine Processing, Department of Materials Science and Engineering, Tsinghua University, Beijing 100084, People's Republic of China

2. School of Engineering and Applied Sciences, Harvard University, Cambridge 02138, USA

The electronic structure, anisotropic elastic and thermal properties of monoclinic $\mathrm{Ca}_{2} \mathrm{Nb}_{2} \mathrm{O}_{7}$ have been investigated by density functional theory (DFT) calculations and further are verified by experimental results. It has been shown that the monoclinic $\mathrm{Ca}_{2} \mathrm{Nb}_{2} \mathrm{O}_{7}$ is a direct band gap insulator with the calculated band gap of $3.07 \mathrm{eV}$ which is comparable with the experimental value of $3.33 \mathrm{eV}$. The bottom of the conduction band (CB) is dominated by the $4 d$ orbitals of the $\mathrm{Nb}$ atoms and the $2 p$ orbitals of $\mathrm{O}$ atoms, while the top of valence band (VB) mainly consists of the $2 p$ orbitals of $\mathrm{O}$ atoms. Calculated sound velocities of different directions show that the faster mixed mode $\left(v_{+}\right)$is much larger than that of slower mixed mode $\left(v_{-}\right)$and pure transverse mode $\left(v_{t}\right)$ in both [100] and [001] directions. The pure longitudinal mode $v_{l}$ has the greatest sound velocity among the three acoustic modes in the [010] direction. According to Clarke's model, monoclinic $\mathrm{Ca}_{2} \mathrm{Nb}_{2} \mathrm{O}_{7}$ has low limit thermal conductivity with $1.43 \mathrm{~W} \cdot \mathrm{m}^{-1} \cdot \mathrm{K}^{-1}$ at high temperature, and minimum thermal conductivity in (100),(110),(010) and (001) planes sensitively depends on the directions.

Keywords: Thermal conductivity; Elastic properties; $\mathrm{Ca}_{2} \mathrm{Nb}_{2} \mathrm{O}_{7}$; First principles calculation

PACS: $71.20 . \mathrm{Ps} ;$ 78.40.Ha

Corresponding author. Tel.: +86 1062772858.

E-mail address: panw@mail.tsinghua.edu.cn (W. Pan). 


\section{Introduction}

Calcium pyroniobate $\left(\mathrm{Ca}_{2} \mathrm{Nb}_{2} \mathrm{O}_{7}\right)$ with pyrochlore structure have been attracted much interest due to their wide applications in piezoelectric, electro-optic, photocatalysis, and electrocatalysts for hydrocarbon oxidation reactions, etc. It was reported that the $\mathrm{Ca}_{2} \mathrm{Nb}_{2} \mathrm{O}_{7}$ exhibits a large negative temperature coefficient of the dielectric constant in the vicinity of ambient temperature [1]. Zhu et al. have demonstrated that $\mathrm{Ca}_{2} \mathrm{Nb}_{2} \mathrm{O}_{7}$ can efficiently degrade rhodamine $\mathrm{B}(\mathrm{RhB})$ under UltraViolet (UV) light irradiation. The photocatalytic activity and photocurrent generation were effectively improved by $\mathrm{Ta}^{5+}$ substitution for $\mathrm{Ca}_{2} \mathrm{Nb}_{2} \mathrm{O}_{7}$ pyrochlore [2]. Recently, solvothermal synthesis of $\mathrm{Ca}_{2} \mathrm{Nb}_{2} \mathrm{O}_{7}$ fine particles and their high photocatalytic activity for water splitting into $\mathrm{H}_{2}$ and $\mathrm{O}_{2}$ under UV light irradiation was reported by Ryu Abe and co-workers [3]. However, besides pyrochlore structure, $\mathrm{Ca}_{2} \mathrm{Nb}_{2} \mathrm{O}_{7}$ also has monoclinic structure with space group $P 2_{1}$. Monoclinic $\mathrm{Ca}_{2} \mathrm{Nb}_{2} \mathrm{O}_{7}$ is constructed by the corner-shared octahedral $\mathrm{NbO}_{6}$ framework layers, and the $\mathrm{Ca}$ atoms located at the cavity constructed by $\mathrm{NbO}_{6}$ units as shown in Fig.1. It was found that monoclinic $\mathrm{Ca}_{2} \mathrm{Nb}_{2} \mathrm{O}_{7}$ could be used as a new laser host materials [4]. $\mathrm{Nd}^{3+}$-doped monoclinic $\mathrm{Ca}_{2} \mathrm{Nb}_{2} \mathrm{O}_{7}$ was reported quite broad absorption bandwidth $(20 \mathrm{~nm})$ at $798 \mathrm{~nm}$ [5], and doped with $\mathrm{Yb}^{3+}$ showed broad absorption and emission bandwidth [6]. Pan et al. have synthesized simultaneously substituted pyrochlore compounds $\left(\mathrm{Ca}_{2} \mathrm{Nb}_{2} \mathrm{O}_{7}\right)_{\mathrm{x}}\left(\mathrm{Gd}_{2} \mathrm{Zr}_{2} \mathrm{O}_{7}\right)_{1-\mathrm{x}}(\mathrm{x}=0,0.05,0.25,0.50,0.75,1)$ for their use as a potential advanced thermal barrier coating (TBC) materials[7] . Recently, niobate with different crystal structures also have attracted much recent attention $[8,9]$.

Nevertheless, electronic structures, mechanical and thermal properties of monoclinic $\mathrm{Ca}_{2} \mathrm{Nb}_{2} \mathrm{O}_{7}$ have been rarely reported systematically. In this paper, combining with the 
experimental investigations, we have investigated the electronic structure, elastic coefficients, bulk modulus, shear modulus, Young's modulus, and thermal properties of $\mathrm{Ca}_{2} \mathrm{Nb}_{2} \mathrm{O}_{7}$ compound systematically by using the first principle calculation based on density functional theory (DFT). Especially, we have found that the sound velocities of compound exhibit strong anisotropic properties. Furthermore, the anisotropic elastic and thermal properties also have been studied according to the calculated elastic data. Theoretical methods used in this paper have been employed to predict the properties of many materials successfully in our previous work [10-14]. Actually, the simulation is an effective method to investigate materials properties [15-18].We hope that the calculated results will contribute to the Materials Genome Initiative project which can accelerate advanced materials discovery [19] and will also extend the range of applications of $\mathrm{Ca}_{2} \mathrm{Nb}_{2} \mathrm{O}_{7}$.

\section{Experimental and computational details}

The ceramic powders of $\mathrm{Ca}_{2} \mathrm{Nb}_{2} \mathrm{O}_{7}$ were synthesized by solid-state reaction method. Rare-earth oxide powders $\mathrm{CaO}$ (>99.5\%, Tianjin Bodi Chemical Industry Co. Ltd) and $\mathrm{Nb}_{2} \mathrm{O}_{5}(99.99 \%$, Sinopharm Chemical Reagent Co. Ltd) were chosen as the reactants. The oxides were weighted to the composition of $\mathrm{Ca}_{2} \mathrm{Nb}_{2} \mathrm{O}_{7}$ stoichiometry. Materials were ball-milled in ethanol by a planetary-mill for 8 hours with $387 \mathrm{r} / \mathrm{min}$. Dry-pressing and uniaxial pressing at $200 \mathrm{MPa}$ were successively applied to prepare the green bodies with proper shape, and then sinter at $1400^{\circ} \mathrm{C}$ for 10 hours. The phase of the specimens was characterized by X-ray diffraction (XRD, D/max-RB, Rigaku, Japan, $\left.\mathrm{Cu} / \mathrm{K}_{a}\right)$. The morphology of the sample was examined by using scanning electron microscopy (SEM, JSM-7001F, JEOL, Japan ). Band gap of monoclinic $\mathrm{Ca}_{2} \mathrm{Nb}_{2} \mathrm{O}_{7}$ was characterized by UV-VIS-NIR spectrometer (UV3600, SHIMADZU, Japan). 
The elastic modulus $(E)$ was measured by the ultrasonic method (Ultrasonic Pulser/Receiver Model 5900 PR, Panametrics, Waltham, MA, USA) . It was calculated as

$$
\begin{gathered}
E=\frac{v_{l}^{2} \rho(1+v)(1-2 v)}{(1-v)} \\
v=\frac{1-2\left(v_{t} / v_{l}\right)^{2}}{2-2\left(v_{t} / v_{l}\right)^{2}}
\end{gathered}
$$

where $v_{l}$ and $v_{t}$ represent longitudinal and transverse acoustic velocities, $v$ the Poisson ratio of the specimens and $\rho$ the density. The real elastic modulus of fully dense specimens $\left(E_{0}\right)$ is given by

$$
E_{0}=\frac{E}{\left(1-\varphi^{2 / 3}\right)^{1.21}}
$$

and $\varphi$ is the porosity of the specimens which is measured according to the Archimedes method.

The thermal diffusivity $(\alpha)$ was measured by laser flash analyzer (Netzsch LFA 427, Bavaria, Germany) from 200 to $1000{ }^{\circ} \mathrm{C}$ in argon atmosphere. The value of total thermal diffusivity was evaluated by Cape-lehman model.

Thermal conductivity $\kappa_{0}$ was calculated by using following equation

$$
\kappa_{0}=\rho \cdot c \cdot \alpha
$$

where $c$ is the heat capacity which was calculated according to Neumann-Kopp law, and $\rho$ is the density of corresponding specimens.

Taking into account the effect of the porosity $(\phi)$, the thermal conductivity of fully dense specimens $(\kappa)$ was modified as

$$
\kappa_{0} / \kappa=1-4 / 3 \phi
$$

All first-principle calculations were performed based on the DFT [20] using CASTEP 
code [21] with plane-wave pseudoptential total energy scheme method [22]. The electronic exchange correlation interactions were processed using the local density approximation (LDA) [21] combining with the generalized gradient approximation (GGA) [23]. In this work, convergence of the lattice parameters and the elastic moduli were checked. It is well known that structural parameters converge quickly even with moderate values of the cutoff energy while accurate values of the elastic constants require a higher cutoff. Total energies on the CASTEP-optimized structures are calculated by integration over a Monkhorst-Pack mesh of $6 \times 2 \times 9 \mathrm{k}$-point in the Brillouin zone. The k-point meshes provide convergence of electronic energies with a $500 \mathrm{eV}$ kinetic cutoff energy. The values of the kinetic energy cutoff and the k-point grid are determined to insure the convergence of total energies. The average force acting on ions is reduced to $1.0 \times 10^{-6} \mathrm{eV}$ atom ${ }^{-1}$. The mean Hellmann-Feynman force acting on each atom is $0.01 \mathrm{eV} \AA^{-1}$. Valence electrons included in this work are $\mathrm{Ca} 3 s^{2}$ $3 p^{6} 4 s^{2}, \mathrm{Nb} 4 s^{2} 4 p^{6} 4 d^{4} 5 s^{1}$, and $\mathrm{O} 2 s^{2} 2 p^{4}$.The present calculation scheme has been successfully used to predict the physical properties of $\mathrm{Ln}_{2} \mathrm{Zr}_{2} \mathrm{O}_{7}(\mathrm{Ln}=\mathrm{La}, \mathrm{Pr}, \mathrm{Nd}, \mathrm{Sm}, \mathrm{Eu}$ and $\mathrm{Gd}$ ) pyrochlore [24] and monazite-type $\mathrm{Ln}^{\mathrm{PO}_{4}}(\mathrm{Ln}=\mathrm{La}, \mathrm{Ce}, \mathrm{Nd}, \mathrm{Sm}, \mathrm{Eu}$ and $\mathrm{Gd})$ [25] in our previous work.

\section{Results and Discussion}

\subsection{Texture and equilibrium lattice constants}

Fig. 2 shows the morphology of the etched surface of polished $\mathrm{Ca}_{2} \mathrm{Nb}_{2} \mathrm{O}_{7}$ sample synthesized by solid-state reaction and heat treated at $1400 \mathrm{~K}$. Bulk density was calculated according to Archimedes method, it is close to $100 \%$. The XRD patterns of the specimen within the range of $20 \sim 70^{\circ}$ is shown in Fig. 3 . It indicates that the specimen is single and 
fully monoclinic $\mathrm{Ca}_{2} \mathrm{Nb}_{2} \mathrm{O}_{7}$ phase according to the standard PDF card (PDF\#74-0390). In order to investigate the texture of compound, the XRD pattern of the $\mathrm{Ca}_{2} \mathrm{Nb}_{2} \mathrm{O}_{7}$ powders was also characterized. The degree of texture $(\beta)$ can be defined as

$$
\beta=\frac{I_{b u l k}(002) / I_{\text {bulk }}(050)}{I_{\text {powder }}(002) / I_{\text {powder }}(050)}
$$

In above equation the planes (002) and (050) refer to two mutually perpendicular crystal planes of monoclinic $\mathrm{Ca}_{2} \mathrm{Nb}_{2} \mathrm{O}_{7}$. According to the $\mathrm{Eq}(6)$, combining with the intensity of peaks of XRD as shown in Fig 3 in range of 32 to 35 degree, the calculated $\beta$ is equal to 1.8 which shows some degree of texture of monoclinic $\mathrm{Ca}_{2} \mathrm{Nb}_{2} \mathrm{O}_{7}$ phase.

As shown in Table 1, we refine the lattice parameters from the XRD results, and it is obvious that LDA slightly underestimates the lattice constants, while GGA overestimates the lattice constants as compared to the experimental values. However, the deviation in lattice parameters evaluated by theoretically and experimentally is less than $3 \%$. So the theoretical method used in this paper can be employed to predict other physical properties of $\mathrm{Ca}_{2} \mathrm{Nb}_{2} \mathrm{O}_{7}$. The stability of compound is identified by formation enthalpy and cohesive energies with the following equations

$$
\begin{gathered}
\Delta H\left(\mathrm{Ca}_{2} \mathrm{Nb}_{2} \mathrm{O}_{7}\right)=E_{\text {total }}\left(\mathrm{Ca}_{2} \mathrm{Nb}_{2} \mathrm{O}_{7}, \mathrm{cell}\right)-n_{1} E(\mathrm{Ca})-n_{2} E(\mathrm{Nb})-n_{3} \frac{1}{2} E\left(\mathrm{O}_{2}\right) \\
E_{\text {coh }}\left(\mathrm{Ca}_{2} \mathrm{Nb}_{2} \mathrm{O}_{7}\right)=E_{\text {total }}\left(\mathrm{Ca}_{2} \mathrm{Nb}_{2} \mathrm{O}_{7}, \text { cell }\right)-n_{1} E_{\text {iso }}(\mathrm{Ca}, \text { atom }) \\
-n_{2} E_{\text {iso }}(\mathrm{Nb}, \text { atom })-n_{3} E_{\text {iso }}(\mathrm{O}, \text { atom })
\end{gathered}
$$

In the $\mathrm{Eq}(7,8), \triangle H\left(\mathrm{Ca}_{2} \mathrm{Nb}_{2} \mathrm{O}_{7}\right)$ refers to the formation enthalpy of $\mathrm{Ca}_{2} \mathrm{Nb}_{2} \mathrm{O}_{7}$, and $E_{\text {total }}$ $\left(\mathrm{Ca}_{2} \mathrm{Nb}_{2} \mathrm{O}_{7}\right)$ the total energy of crystal. $E(\mathrm{Ca})(E(\mathrm{Nb}))$ is the corresponding total energy of crystal $\mathrm{Ca}(\mathrm{Nb})$ in the ground state while $E\left(\mathrm{O}_{2}\right)$ is the total energy of the $\mathrm{O}_{2}$ molecule which 
is computed by using a cubic supercell model within a length of $10 \AA . E_{\text {coh }}\left(\mathrm{Ca}_{2} \mathrm{Nb}_{2} \mathrm{O}_{7}\right)$ refers to the cohesive energy of compound and $E_{i s o}(X, X=C a, N b, O)$ is the energy of an isolated atom which is calculated using the supercell method. As shown in the Table 1, formation enthalpy and the cohesive energy of monoclinic $\mathrm{Ca}_{2} \mathrm{Nb}_{2} \mathrm{O}_{7}$ are all negative indicating that the compound is stable in the ground state. Furthermore, monoclinic $\mathrm{Ca}_{2} \mathrm{Nb}_{2} \mathrm{O}_{7}$ is more stable than the cubic $\mathrm{Ca}_{2} \mathrm{Nb}_{2} \mathrm{O}_{7}$ pyrochlore due to lower formation enthalpy and the cohesive energy.

\subsection{Electronic structure}

Fig. 4 shows the calculated band structure of monoclinic $\mathrm{Ca}_{2} \mathrm{Nb}_{2} \mathrm{O}_{7}$. It shows that monoclinic $\mathrm{Ca}_{2} \mathrm{Nb}_{2} \mathrm{O}_{7}$ is a typical direct band gap insulators with calculated band gap of 3.07 $\mathrm{eV}$ comparison to the experimental results of $3.33 \mathrm{eV}$ (in Fig .6). It is known that the first-principle calculated band-gap by LDA is less than the experimental value due to the insufficient description of the exchange correlation in the DFT calculations. According to Fig. 4, the electronic band dispersion curves for both the valence and conduction bands are smooth and flat, implying the strong ionic bonding of this crystal structure. Angular projected density of states (PDOS) provides more details about the composition of band structures of different atoms and orbitals for compound, and the results are shown in Fig. 5. It is shown that, for monoclinic $\mathrm{Ca}_{2} \mathrm{Nb}_{2} \mathrm{O}_{7}$, the bottom of the conduction band is dominated by the $4 d$ orbitals of the $\mathrm{Nb}$ atoms and the $2 p$ orbitals of $\mathrm{O}$ atoms, while the top of valence band mainly consists of the $2 p$ orbitals of $\mathrm{O}$ atoms. $\mathrm{Ca}$ atoms do not contribute to both the conduction band and valence band.

\subsection{Anisotropy in elasticity and sound velocities}


Owing to the lower symmetry of the monoclinic structure, the full sets of elastic constants of monoclinic $\mathrm{Ca}_{2} \mathrm{Nb}_{2} \mathrm{O}_{7}$ are relatively difficult to be available from experiments. The calculated elastic constants of monoclinic $\mathrm{Ca}_{2} \mathrm{Nb}_{2} \mathrm{O}_{7}$ by LDA combining with $\mathrm{CaO}$ and $\mathrm{Nb}_{2} \mathrm{O}_{5}$ are shown in Table 2. By comparison, the results of cubic $\mathrm{Ca}_{2} \mathrm{Nb}_{2} \mathrm{O}_{7}$ pyrochlore are also given. According to Table 2 , despite of negative elastic constants $\left(\mathrm{C}_{25}, \mathrm{C}_{35}\right.$ and $\left.\mathrm{C}_{46}\right)$ obtained, the crystal structure is still stable according to the theory of Born-Huang criterion and is further verified by the formation enthalpy and cohesive energy(in Table 1). The principal elements $\left(\mathrm{C}_{11}, \mathrm{C}_{22}\right.$ and $\left.\mathrm{C}_{33}\right)$ in the stiffness matrix are relatively large (>200 GPa), while shear-compression elements $\left(\mathrm{C}_{15}, \mathrm{C}_{25}\right.$ and $\left.\mathrm{C}_{35}\right)$ are small as compared with other non-zero diagonal elements which depend on the orientation of the crystal. Actually, the principal elastic constants are related to the chemical bonds in compound. From calculated results of Table 2, the value of $\mathrm{C}_{11}$ is larger than that of $\mathrm{C}_{22}$ and $\mathrm{C}_{33}$, implying that chemical bonds strength in the [100] direction is stronger than in directions [010] and [001]. On the other hand, the deviation between the $\mathrm{C}_{22}$ and $\mathrm{C}_{33}$ is small, and the anisotropy of elasticity at (100) plane is relatively weak.

The modulus is fundamental parameter for characterizing the mechanical and thermal properties of compounds. According to the calculated elastic constants, the isothermal bulk modulus $B$, shear modulus $G$, and Young's modulus $E$ can be evaluated. For bulk polycrystalline materials, the Voigt and Reuss's approximation which represents the upper and lower limits of the elastic parameters are widely used to estimate the mechanical moduli [27]. The calculated mechanical moduli with comparison to experimental results are shown in Table 3. Overall, the LDA slightly overestimates the modulus as compared with the experimental value due to the underestimated lattice constants. Furthermore, for the 
theoretical calculations the material is considered as the perfect crystal model, but actual material has a variety of defects which lead to a certain degree of reduction of modulus. Form Table 3, one also can see that the modulus of cubic $\mathrm{Ca}_{2} \mathrm{Nb}_{2} \mathrm{O}_{7}$ pyrochlore is larger than that of monoclinic $\mathrm{Ca}_{2} \mathrm{Nb}_{2} \mathrm{O}_{7}$. It which can be understood by the following analytic argument: Firstly, the monoclinic $\mathrm{Ca}_{2} \mathrm{Nb}_{2} \mathrm{O}_{7}$ structures are not relatively incompressible due to its low-symmetry. Secondly, the mean $\mathrm{Nb}-\mathrm{O}$ and $\mathrm{Ca}-\mathrm{O}$ bond lengths of monoclinic $\mathrm{Ca}_{2} \mathrm{Nb}_{2} \mathrm{O}_{7}$ are larger than that of the cubic $\mathrm{Ca}_{2} \mathrm{Nb}_{2} \mathrm{O}_{7}$ pyrochlore. It is well known that Poisson's ratio is an important physical parameter of materials. Generally speaking, the larger the Poisson's ratio, the softer the material. The Poisson's ratios $(\sigma=0.26)$ of monoclinic $\mathrm{Ca}_{2} \mathrm{Nb}_{2} \mathrm{O}_{7}$ are typical ceramics which are in the range of $0.25-0.30$. Nevertheless, the relatively large Poisson's ratio implies that monoclinic $\mathrm{Ca}_{2} \mathrm{Nb}_{2} \mathrm{O}_{7}$ compound are machinable ceramics. The Vickers micro-hardness is evaluated by using the empirical rule between hardness and shear modulus $G=6.78 \mathrm{Hv}$ [28], and the estimated hardness of monoclinic $\mathrm{Ca}_{2} \mathrm{Nb}_{2} \mathrm{O}_{7}$ compound is 10.9 $\mathrm{GPa}$ which is comparable with rare earth stannate pyrochlores (10-12 GPa) [29]. By comparison, the cubic $\mathrm{Ca}_{2} \mathrm{Nb}_{2} \mathrm{O}_{7}$ has larger Vickers hardness due to its larger shear modulus which may be result from the stronger chemical bonds and higher symmetry.

According to the best of our knowledge, the anisotropy of mechanical and thermal properties of monoclinic $\mathrm{Ca}_{2} \mathrm{Nb}_{2} \mathrm{O}_{7}$ compound are lack of reporting. The universal elastic anisotropic index $A^{U}$ proposed by Shivakumar I. Ranganathan et al.is widely used to describe the anisotropy of material which is given by [30]

$$
A^{U}=5 \frac{G_{V}}{G_{R}}+\frac{B_{V}}{B_{R}}-6 \geq 0
$$

where subscripts $V$ and $R$ represent the Voigt and Reuss's estimations for $B$ and $G$, 
respectively. If $A^{U}=0$, it refers to a locally isotropic single crystal, and the larger $A^{U}$ means the more pronounced anisotropic. According to values of $A^{U}$ as shown in Table 3, the monoclinic $\mathrm{Ca}_{2} \mathrm{Nb}_{2} \mathrm{O}_{7}$ appears significantly anisotropic comparison to the cubic $\mathrm{Ca}_{2} \mathrm{Nb}_{2} \mathrm{O}_{7}$ pyrochlore. The conclusion is confirmed by the modulus of compounds. As shown in Table 4, Young's modulus of $\mathrm{Ca}_{2} \mathrm{Nb}_{2} \mathrm{O}_{7}$ of three principal directions has been calculated, and $\mathrm{E}_{\mathrm{x}}>\mathrm{E}_{\mathrm{y}}>$ $\mathrm{E}_{\mathrm{z}}$ is obtained for monoclinic $\mathrm{Ca}_{2} \mathrm{Nb}_{2} \mathrm{O}_{7}$ while $\mathrm{E}_{\mathrm{x}}=\mathrm{E}_{\mathrm{y}}=\mathrm{E}_{\mathrm{z}}$ for cubic $\mathrm{Ca}_{2} \mathrm{Nb}_{2} \mathrm{O}_{7}$. It is well known that the Poisson's ratio of monoclinic crystal class is a tensor of rank 2. According to Table 4, Poisson's ratio of monoclinic $\mathrm{Ca}_{2} \mathrm{Nb}_{2} \mathrm{O}_{7}$ has obvious anisotropic while cubic $\mathrm{Ca}_{2} \mathrm{Nb}_{2} \mathrm{O}_{7}$ pyrochlore shows isotropic.

The sound velocities in a crystal play an important role in the thermal properties of materials. Generally speaking, there are three acoustic modes in each propagating direction: two pure transverse modes and one pure longitudinal mode for the system with high symmetry [31] . However, this is no longer valid for the monoclinic crystal system [32]. The dependence of sound velocity on the propagating direction can be deduced from the solutions of the Christoffel equation [33]. The equations used for calculating sound velocity in this work are given in Appendix. According to the Eqs (A3-A5), the calculated sound velocities of different directions are given in Table 5. It is shown that the velocity of the faster mode $\left(v_{+}\right)$is greater than that of the $v_{t}$ and $v_{-}$modes in both [100] and [001] directions. The pure longitudinal mode $v_{l}$ has the greatest sound velocity among the three acoustic modes in the [010] direction. In all principal directions, the slower mode $v$ - has the lowest velocity. It is easily understood that results arise from the different Cartesian coordinate system is chosen for calculating the elastic constants.

\subsection{Thermal conductivity and anisotropy of minimum phonon thermal conductivity}


The thermal conductivity of insulator describes the diffusivity of heat flow in a temperature gradient. The thermal conductivity of compound at low temperature decreases smoothly with the increasing temperature as shown in Fig. 7 However, remarkable increase in the thermal conductivity with the increase in temperature is observed at high temperature due to the heat radiation. According to the Stefan-Boltzmann law, heat radiation becomes more and more pronounced when the temperature increases. If the radiation heat transfer is ignored, when the temperature is much higher than Debye temperature, the phonon mean free path length $l$ reaches to the scale of lattice parameter, and the minimum thermal conductivity becomes independent of temperature [34,35]. Clarke [34] have proposed a useful formula to calculate the minimum thermal conductivity of an insulator material as follow

$$
\kappa_{\min , \text { Clark }}=0.87 k_{B} \Omega^{-2 / 3}(E / \rho)^{1 / 2}
$$

and

$$
\Omega=\frac{M}{n \rho N_{A}}
$$

In Eq.(10) and (11), $k_{B}$ is Boltzmann's constant, $M$ the molecular mass, $N_{A}$ the Avogadro's number, $\rho$ the density, $E$ the elastic modulus (Young's modulus), and $n$ the number of atoms in the molecule. Based on Einstein's model, Cahill [36] also proposed thermal conductivity by a wide range of amorphous solids and highly disordered crystals. The minimum thermal conductivity at high temperature limit is given by

$$
\kappa_{\text {min, Cahill }}=\frac{k_{B}}{2.48} n^{2 / 3}\left(2 v_{t}+v_{l}\right)
$$

where $n$ is the density of number of atoms per volume, $v_{t}$ and $v_{l}$ are sound velocities of 
transverse wave and longitudinal wave, respectively. According to the density $\rho$, calculated moduli and sound velocity, the minimum thermal conductivity can be deduced. As shown in Table 6, two types of minimum thermal conductivities are close to each other and the values obtained by Cahill's model are slightly larger than that of Clarke's model. It is worth noting that the predicted minimum thermal conductivity is the intrinsic thermal conductivity of the perfect crystals at high temperature. Furthermore, most previous studies assume that compounds are opaque materials. Actually, as mentioned above, insulating materials are usually used at high temperature or even ultra-high temperatures, where heat radiation becomes more and more pronounced with increasing temperature [37]. This conclusion has been confirmed from the experimental results as shown in Fig 7.

The anisotropy of thermal properties has a great influence on the overall properties of the materials. The monoclinic $\mathrm{Ca}_{2} \mathrm{Nb}_{2} \mathrm{O}_{7}$ has an anisotropic minimum thermal conductivity owing to the deviation of $C_{\mathrm{ij}}$ in different directions. Thermal conductivity of a material is related to Young's modulus and the formal relation is determined using [38]

$$
S_{111}^{\prime}=\sum_{n=1}^{3} \sum_{m=1}^{3} \sum_{p=1}^{3} \sum_{q=1}^{3} S_{n m p q} l_{1 n} l_{1 m} l_{1 p} l_{1 q}
$$

where $S_{111}^{\prime}$ is $1 / E$, and $S_{n m p q}$ are the elastic compliance matrix which can be calculated by the first principle. In above $\mathrm{Eq}(13), l_{n}, l_{m}, l_{p}$, and $l_{q}$ are the directional cosines of the new axis in the rotated coordinate system with respect to the original coordinates. According to the Eq.(13) combining with the Eq.(10), the anisotropy of Young's modulus will lead to the anisotropic minimum thermal conductivity. The planar projections of directional dependences of minimum thermal conductivity of monoclinic $\mathrm{Ca}_{2} \mathrm{Nb}_{2} \mathrm{O}_{7}$ are shown in Fig. 8. The pronounced anisotropy of minimum thermal conductivity depends on directions is 
obtained in (100),(010),(001) and (001) crystallographic planes. The shape of these planar contours are result from the related anisotropy in elasticity. It is shown that the dependences of thermal conductivities on propagating direction at (010) plane has more pronounced anisotropic than that of other planes. However, Jacquot. A et al. [39] reported that the total lattice thermal conductivity of monoclinic system crystal is isotropic because the $v_{t}$ has very weak dependence on direction. Actually, more strict treatment of anisotropy in lattice thermal conductivity involves the computation of phonon dispersions and applying the relaxation time approximation for phonon scattering. Gr ü neisen constant has also importance to the lattice thermal conductivity which are beyond the current discussion.

\section{Conclusions}

Texture, electronic structure, anisotropic elastic and thermal properties of monoclinic $\mathrm{Ca}_{2} \mathrm{Nb}_{2} \mathrm{O}_{7}$ have been studied by both first-principle calculations and experimental investigations. The calculated lattice parameters are in good agreement with the experimental results and both the formation enthalpy and cohesive energies of monoclinic $\mathrm{Ca}_{2} \mathrm{Nb}_{2} \mathrm{O}_{7}$ is negative which indicates that the compound is stable in the ground state. It is shown that the monoclinic $\mathrm{Ca}_{2} \mathrm{Nb}_{2} \mathrm{O}_{7}$ is typical insulator with a wide band-gap between valence band and conduction band states. The monoclinic $\mathrm{Ca}_{2} \mathrm{Nb}_{2} \mathrm{O}_{7}$ bulk shows texture which is verified by X-ray diffraction analysis. According to Clarke's model, the minimum thermal conductivity of monoclinic $\mathrm{Ca}_{2} \mathrm{Nb}_{2} \mathrm{O}_{7}$ is $1.43 \mathrm{~W} \cdot \mathrm{m}^{-1} \cdot \mathrm{K}^{-1}$. However, remarkable increase of the experimental thermal conductivity with increasing temperature is observed at high temperature due to the heat radiation. The calculated Poisson's ratios of compound are equal to 0.26 and $G / B$ equal to 0.57 , implying that monoclinic $\mathrm{Ca}_{2} \mathrm{Nb}_{2} \mathrm{O}_{7}$ is a machinable ceramic. It is also shown that the minimum thermal conductivities, medium elastic properties and 
sound velocities of phase have obvious directional dependence. We hope that these results will shed light on the development and applications of monoclinic $\mathrm{Ca}_{2} \mathrm{Nb}_{2} \mathrm{O}_{7}$ compound.

\section{Acknowledgment}

This research is supported by National Science Foundation of China (No. 50990302).

\section{Appendix Anisotropy sound velocities in monoclinic symmetry}

For monoclinic symmetry, the sound velocities in a specific propagating direction are calculated by solving the eigenvalues of the following eigen function:

$$
\left[\begin{array}{ccc}
\Gamma_{11}-\rho v^{2} & \Gamma_{12} & \Gamma_{13} \\
\Gamma_{21} & \Gamma_{22}-\rho v^{2} & \Gamma_{23} \\
\Gamma_{31} & \Gamma_{32} & \Gamma_{33}-\rho v^{2}
\end{array}\right]\left[\begin{array}{l}
u_{1} \\
u_{2} \\
u_{3}
\end{array}\right]=0
$$

where $u_{j}$ is displacement vector,$v$ the sound velocity, $\rho$ the density. In above $\mathrm{Eq}(\mathrm{A} 1)$, matrix element $\Gamma_{i j}$ is given as

$$
\left\{\begin{array}{c}
\Gamma_{11}=C_{11} l_{1}^{2}+C_{66} l_{2}^{2}+C_{55} l_{3}^{2}+2 C_{15} l_{1} l_{3} \\
\Gamma_{22}=C_{66} l_{1}^{2}+C_{22} l_{2}^{2}+C_{44} l_{3}^{2}+2 C_{46} l_{1} l_{3} \\
\Gamma_{33}=C_{55} l_{1}^{2}+C_{44} l_{2}^{2}+C_{33} l_{3}^{2}+2 C_{35} l_{1} l_{2} \\
\Gamma_{12}=\Gamma_{21}=\left(C_{12}+C_{66}\right) l_{1} l_{2}+\left(C_{46}+C_{25}\right) l_{2} l_{3} \\
\Gamma_{13}=\Gamma_{31}=C_{15} l_{1}^{2}+C_{46} l_{2}^{2}+C_{33} l_{3}^{2}+\left(C_{13}+C_{55}\right) l_{1} l_{3} \\
\Gamma_{23}=\Gamma_{32}=\left(C_{46}+C_{25}\right) l_{1} l_{2}+\left(C_{23}+C_{44}\right) l_{2} l_{3}
\end{array}\right.
$$

where $l_{1}, l_{2}$ and $l_{3}$ are the directional cosines which defined by $l_{1}=\cos \alpha, l_{2}=\cos \beta, l_{1}=\cos \gamma$, and $\alpha, \beta$ and $\gamma$ are the angles refer to the $\mathrm{x}, \mathrm{y}$ and $\mathrm{z}$ axes, respectively. By solving the Eq. (A1) for three principal axes:[100], [010] and [001] directions the eigenvalues in three directions are given in Eqs. (A3)-(A5). 
$\left[\begin{array}{lll}1 & 0 & 0\end{array}\right]$ :

$$
\begin{gathered}
v_{t}=\sqrt{C_{66} / \rho} \\
v_{+}=\sqrt{\frac{\left(\mathrm{C}_{11}+\mathrm{C}_{55}\right)+\left(\mathrm{C}_{11}^{2}+4 \mathrm{C}_{15}^{2}-2 \mathrm{C}_{11} \mathrm{C}_{55}+\mathrm{C}_{55}^{2}\right)^{1 / 2}}{2 \rho}} \\
v_{-}=\sqrt{\frac{\left(\mathrm{C}_{11}+\mathrm{C}_{55}\right)-\left(\mathrm{C}_{11}^{2}+4 \mathrm{C}_{15}^{2}-2 \mathrm{C}_{11} \mathrm{C}_{55}+\mathrm{C}_{55}^{2}\right)^{1 / 2}}{2 \rho}}
\end{gathered}
$$

[010]:

$$
\begin{gathered}
v_{l}=\sqrt{C_{22} / \rho} \\
v_{t+}=\sqrt{\frac{\left(\mathrm{C}_{44}+\mathrm{C}_{66}\right)+\left(\mathrm{C}_{44}^{2}+4 \mathrm{C}_{46}^{2}-2 \mathrm{C}_{44} \mathrm{C}_{66}+\mathrm{C}_{66}^{2}\right)^{1 / 2}}{2 \rho}} \\
v_{t-}=\sqrt{\frac{\left(\mathrm{C}_{44}+\mathrm{C}_{66}\right)-\left(\mathrm{C}_{44}^{2}+4 \mathrm{C}_{46}^{2}-2 \mathrm{C}_{44} \mathrm{C}_{66}+\mathrm{C}_{66}^{2}\right)^{1 / 2}}{2 \rho}}
\end{gathered}
$$

[001]:

$$
\begin{gathered}
v_{t}=\sqrt{C_{44} / \rho} \\
v_{+}=\sqrt{\frac{\left(\mathrm{C}_{33}+\mathrm{C}_{55}\right)+\left(\mathrm{C}_{33}^{2}+4 \mathrm{C}_{35}^{2}-2 \mathrm{C}_{33} \mathrm{C}_{55}+\mathrm{C}_{55}^{2}\right)^{1 / 2}}{2 \rho}} \\
v_{+}=\sqrt{\frac{\left(\mathrm{C}_{33}+\mathrm{C}_{55}\right)-\left(\mathrm{C}_{33}^{2}+4 \mathrm{C}_{35}^{2}-2 \mathrm{C}_{33} \mathrm{C}_{55}+\mathrm{C}_{55}^{2}\right)^{1 / 2}}{2 \rho}}
\end{gathered}
$$

In Eqs.(A3)-(A5),the $v_{t}\left(v_{l}\right)$ represents transverse mode (pure longitudinal mode), and both $v_{+}$and $v_{-}$are mixed modes. 


\section{References}

[1] R.J. Cava, J.J. Krajewski, R.S. Roth, Low temperture coeficient bulk dielectrics in the $\mathrm{Ca}_{2} \mathrm{Nb}_{2} \mathrm{O}_{7}-$ $\mathrm{Ca}_{2} \mathrm{Ta}_{2} \mathrm{O}_{7}$ system, Mater. Res. Bull. 33 (1998) 527-532.

[2] L. Zhang, H. Fu, C. Zhang, Y. Zhu, Effects of $\mathrm{Ta}^{5+}$ Substitution on the Structure and Photocatalytic Behavior of the $\mathrm{Ca}_{2} \mathrm{Nb}_{2} \mathrm{O}_{7}$ Photocatalyst, J. Phys. Chem. C 112 (2008) 3126-3133.

[3] A. Nakamura, O. Tomita, M. Higashi, S. Hosokawa, T. Tanaka, R. Abe, Solvothermal Synthesis of $\mathrm{Ca}_{2} \mathrm{Nb}_{2} \mathrm{O}_{7}$ Fine Particles and Their High Activity for Photocatalytic Water Splitting into $\mathrm{H}_{2}$ and $\mathrm{O}_{2}$ under UV Light Irradiation, Chem. Lett. 44 (2015) 1001-1003.

[4] X. Long, X. Han, Growth of nonlinear optical calcium pyroniobate crystal, J. Cryst. Growth 275 (2005) 492-495.

[5] X. Long, X. Han, Spectral properties of $\mathrm{Nd}^{3+}: \mathrm{Ca}_{2} \mathrm{Nb}_{2} \mathrm{O}_{7}$ crystal, J. Lumin.118 (2006) 79-82.

[6] G. Yao, Y. Cheng, F. Wu, X. Xu, L. Su, J. Xu, Spectral investigation of Yb-doped calcium pyroniobate crystal, J. Cryst. Growth 310 (2008) 725-730.

[7] M. Zhao, X. Ren, W. Pan, Mechanical and thermal properties of simultaneously substituted pyrochlore compounds $\left(\mathrm{Ca}_{2} \mathrm{Nb}_{2} \mathrm{O}_{7}\right) \mathrm{x}\left(\mathrm{Gd}_{2} \mathrm{Zr}_{2} \mathrm{O}_{7}\right)_{1-\mathrm{x}}$, J. Eur. Ceram. Soc. 35 (2015) 1055-1061.

[8] C.L. Fu, H.J. Liu, G Chen, W Cai, X.L. Deng, Microstructure and electric properties of strontium niobate ceramics, Ceram. Int. 38 (2012) 2601-2603.

[9] H.B. Li, C.C. Wang, H Wang, D Zhang, N Zhang, Low-frequency dielectric properties of $\mathrm{CaNb}_{2} \mathrm{O}_{6}$ ceramics over a wide temperature range, Ceram. Int. 41 (2015) 14773-14779.

[10] J. Yang, J. Feng, M. Zhao, X. Ren, W. Pan, Electronic structure, mechanical properties and anisotropy of thermal conductivity of Y-Si-O-N quaternary crystals, Comp. Mater. Sci. 109 (2015) 231-239.

[11] J. Feng, B. Xiao, R. Zhou, W. Pan, Thermal expansions of $\mathrm{Ln}_{2} \mathrm{Zr}_{2} \mathrm{O}_{7}(\mathrm{Ln}=\mathrm{La}, \mathrm{Nd}, \mathrm{Sm}$, and $\mathrm{Gd})$ pyrochlore, J. Appl. Phys. 111 (2012) 103535.

[12] J. Feng, B. Xiao, C. Wan, Z. Qu, R. Zhou, W. Pan, Electronic and elastic properties of a double perovskite slab-rocksalt layer of $\mathrm{Eu}_{2} \mathrm{SrAl}_{2} \mathrm{O}_{7}$ investigated by LSDA+U, Solid State Commun. 151 (2011) 1326-1330.

[13] Z. Huang, J. Feng, W. Pan, First-principles calculations of structural and thermodynamic properties of $\mathrm{Y}_{3} \mathrm{Al}_{5} \mathrm{O}_{12}$, Solid State Commun.151 (2011) 1559-1563.

[14] Z. Huang, L. Zhang, J. Feng, W. Pan, Physical properties of high-pressure scheelite $\mathrm{YVO}_{4}$ from density functional calculations, Comp. Mater. Sci. 69 (2013) 527-532.

[15] I.M.C. Payne, M.P. Teter, D.C. Ailan, T.A. Arias, J.D. Joannopouios, Iterative minimization techniques for ab initio total-energy calculations: molecular dynamics and conjugate gradients, Rev. Mod. Phys. 64 (1992) 1045-1097.

[16] R.H. Zhang, Z.B. Lu, W Shi, S.L. Leng, B.C Tang, Low friction of diamond sliding against $\mathrm{Al}_{2} \mathrm{O}_{3}$ ceramic ball based on the first principles calculations, Surf. Coat. Technol. 283 (2015) 129-134.

[17] R.H. Zhang, L.P. Wang, Effect of compressive strain on the Hertzian contact of self-mated fluorinated carbon films, RSC Adv. 5 ( 2015) 41604-41607.

[18] R.H. Zhang, L.P. Wang, Z.B. Lu, Probing the intrinsic failure mechanism of fluorinated amorphous carbon film based on the first-principles calculations, Sci. Rep. 5 (2015) 9419(1-9).

[19] http://www.whitehouse.gov/sites/default/files/microsites/ostp/materials. genome initiative-final, (2011) 1-18.

[20] R.O. Jones, O. Gunarsson, The density functional formalism, its applications and prospects, Rev.Mod.Phys. 61 (1989) 689-746.

[21] M.D. Segall, J.D.L. Philip, M.J. Probert, C.J. Pickard, P. J, Hasnip, S.J. Clark, M.C. Payne, First-principles simulation: ideas, illustrations and the CASTEP code, J. Phys.: Condens. Matter 14 (2002) 
$2717-2744$.

[22] G. Kresse, D. Joubert, From ultrasoft pseudopotentials to the projector augmented-wave method, Phys. Rev. B 59 (1999).

[23] J.P. Perdew, K. Burke, Y. Wang, Generalized gradient approximation for the exchange-correlation hole of a many-electron system, Phys. Rev. B 54 (1996) 16533-16539.

[24] J. Feng, B. Xiao, C.L. Wan, Z.X. Qu, Z.C. Huang, J.C. Chen, R. Zhou, W. Pan, Electronic structure, mechanical properties and thermal conductivity of $\mathrm{Ln}_{2} \mathrm{Zr}_{2} \mathrm{O}_{7}$ ( $\mathrm{Ln}=\mathrm{La}, \mathrm{Pr}, \mathrm{Nd}, \mathrm{Sm}, \mathrm{Eu}$ and $\mathrm{Gd}$ ) pyrochlore, Acta. Mater 59 (2011) 1742-1760.

[25] J. Feng, B. Xiao, R. Zhou, W. Pan, Anisotropy in elasticity and thermal conductivity of monazite-type $\mathrm{REPO}_{4}(\mathrm{RE}=\mathrm{La}, \mathrm{Ce}, \mathrm{Nd}, \mathrm{Sm}, \mathrm{Eu}$ and $\mathrm{Gd}$ ) from first-principles calculations, Acta. Mater 61 (2013) 7364-7383.

[26] N. Ishizawa, F. Marumo, S. Iwa, M. Kimura,T. Kawamura, Compounds with Perovskite-Type Slabs. III. The Structure of a Monoclinic Modification of $\mathrm{Ca}_{2} \mathrm{Nb}_{2} \mathrm{O}_{7}$, Acta Cryst. B 36 (1980) 763-766.

[27] D.H. Chung, The Voigt-Reuss-Hill (VRH) Approximation and the Elastic Moduli of Polycrystalline $\mathrm{ZnO}, \mathrm{TiO}_{2}$ (Rutile), and $\alpha-\mathrm{Al}_{2} \mathrm{O}_{3}$, J. Appl. Phys. 39 (1968) 2777-2782.

[28] X. Jiang, J. Zhao, X. Jiang, Correlation between hardness and elastic moduli of the covalent crystals, Comp. Mater. Sci. 50 (2011) 2287-2290.

[29] J. Feng, B. Xiao, R. Zhou, W. Pan, Thermal expansion and conductivity of $\mathrm{RE}_{2} \mathrm{Sn}_{2} \mathrm{O}_{7}$ (RE=La, Nd, Sm, Gd, Er and Yb) pyrochlores, Scripta. Mater. 69 (2013) 401-404.

[30] S.I. Ranganathan, M. Ostoja-Starzewski, Universal Elastic Anisotropy Index, Phys. Rev. Lett. 101 (2008) 055504(1-4).

[31] K. Brugger, Pure Modes for Elastic Waves in Crystals, J. Appl. Phys. 36 (1965) 759-768.

[32] Kei Lau, A. K. McCurdy, Elastic anisotropy factors for orthorhombic, tetragonal, and hexagonal crystals. Phys. Rev. B 58(1998) 8980-8984.

[33] S.V. Goldin, Physical interpretation of degeneracies of the Christoffel equation in the theory of anisotropic elasticity, Geophys. Prospect. 61 (2013) 1084-1098.

[34] D.R. Clarke, Materials selection guidelines for low thermal conductivity thermal barrier coatings, Surf.Coat.Technol. 163-164 (2003) 67-74.

[35] D.R. Clarke, C.G. Levi, Materials design for the next generation thermal barrier coatings, Annu.

Rev. Mater. Res. 33 (2003) 383-417.

[36] D.G. Cahill, S.K. Watson, R.O. Pohl, Lower limit to the thermal conductivity of disordered crystals, Phys. Rev. B 46 (1992) 6131-6140.

[37] S. Akamine, M. Fujita, Controlling heat radiation for development of high-temperature insulating materials, J. Eur. Ceram. Soc. 34 (2014) 4031-4036.

[38] Y. He, R. B. Schwarz, A. Migliori, Elastic constants of single crystal y - TiAl, J. Mater. Res. 10 (1995) $1187-1195$.

[39] A. Jacquot, B. Bayer, M. Winkler, H. Böttner, M. Jaegle, Coupled theoretical interpretation and experimental investigation of the anisotropy of the lattice thermal conductivity of $\mathrm{Bi}_{2} \mathrm{Te}_{3}$ single crystal, $\mathrm{J}$ Solid State Chem. 193 (2012) 105-108. 

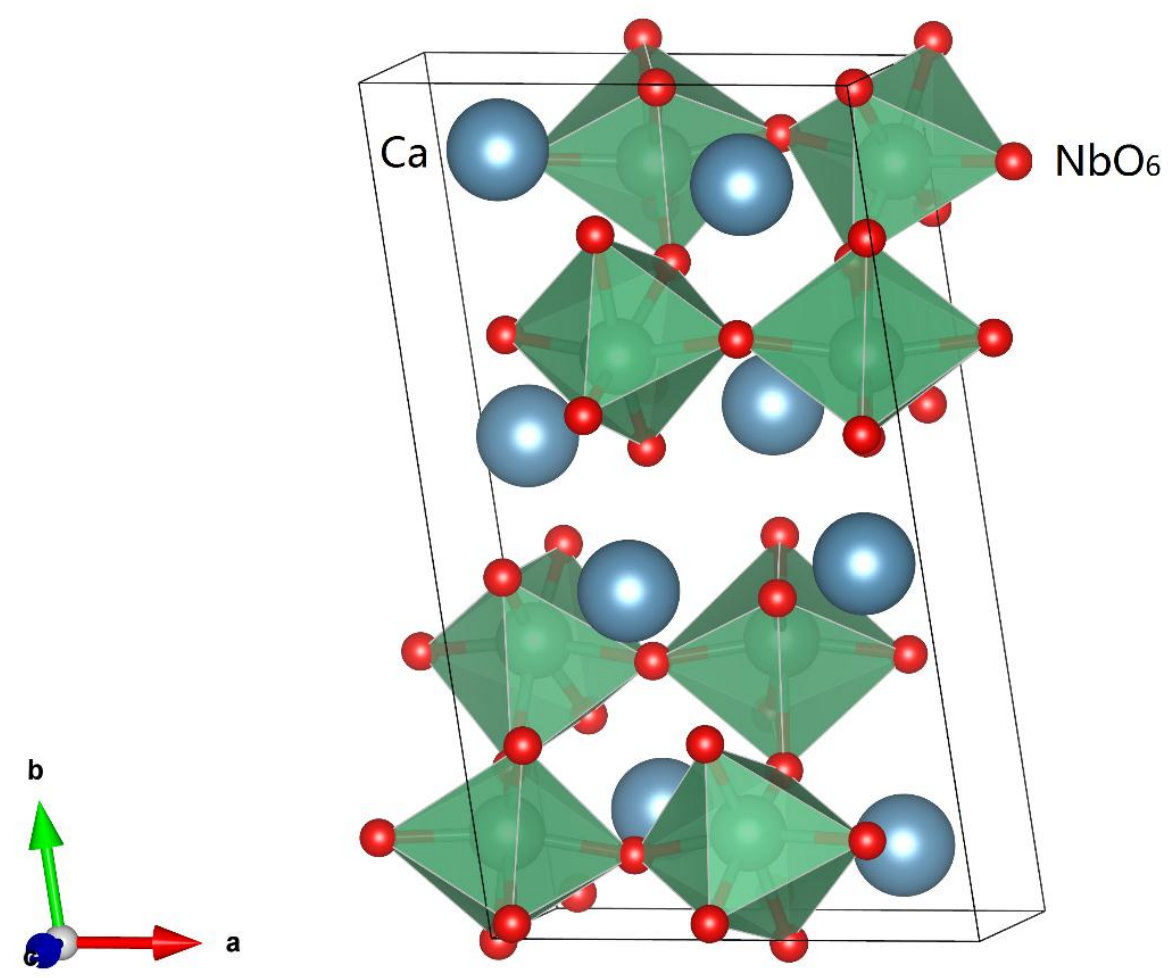

Fig. 1

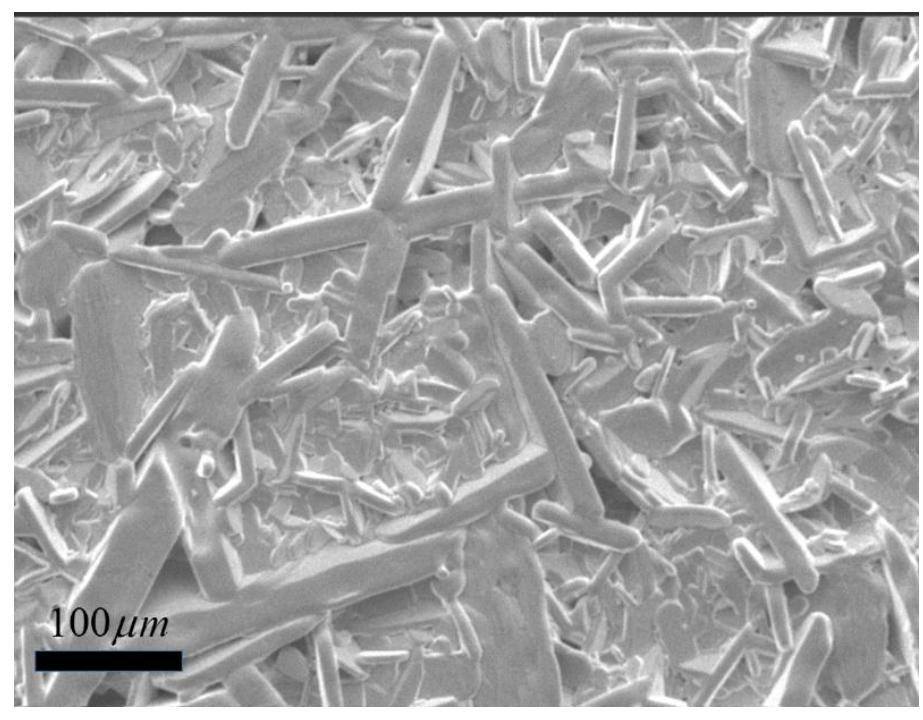

Fig. 2 


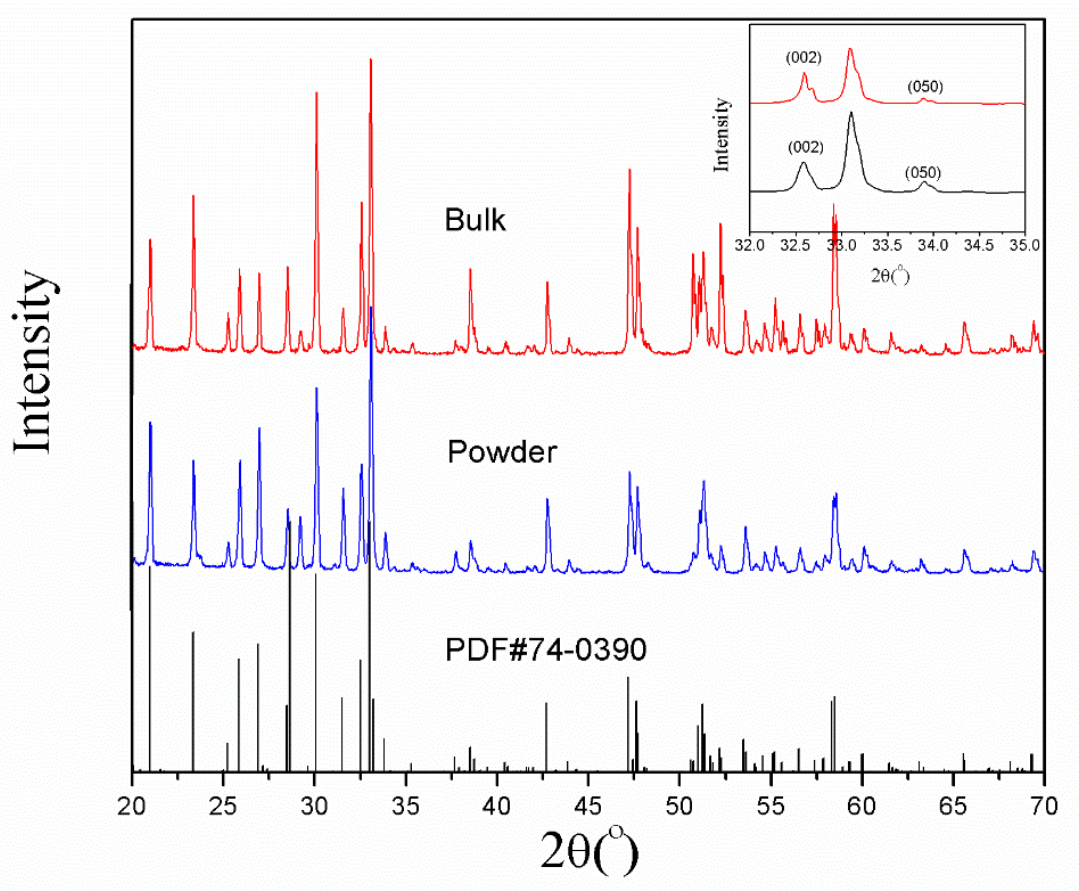

Fig. 3

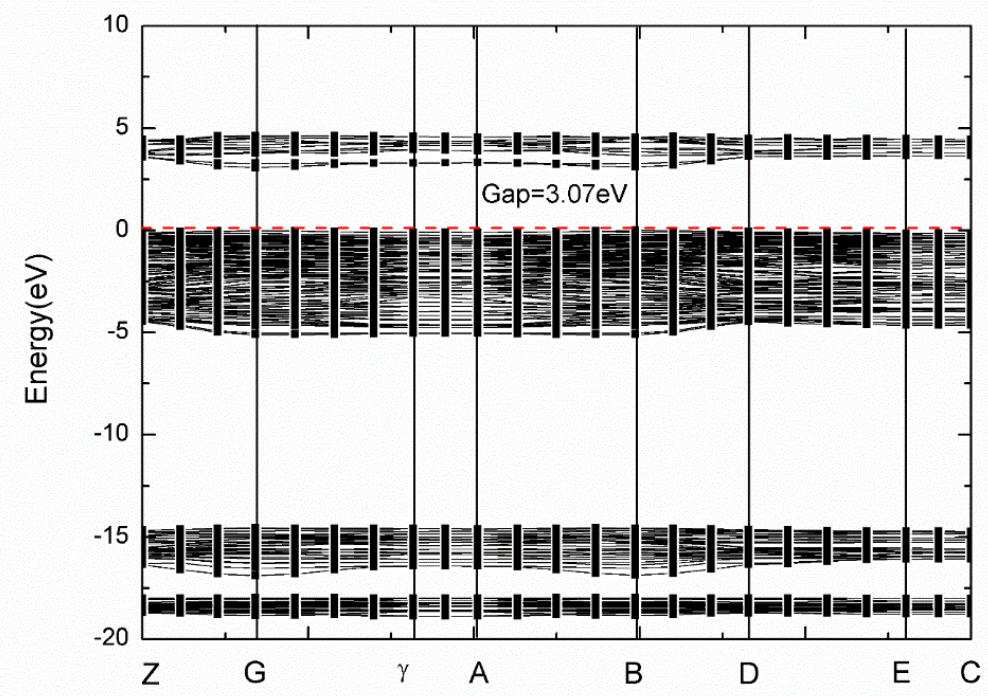

Fig. 4 


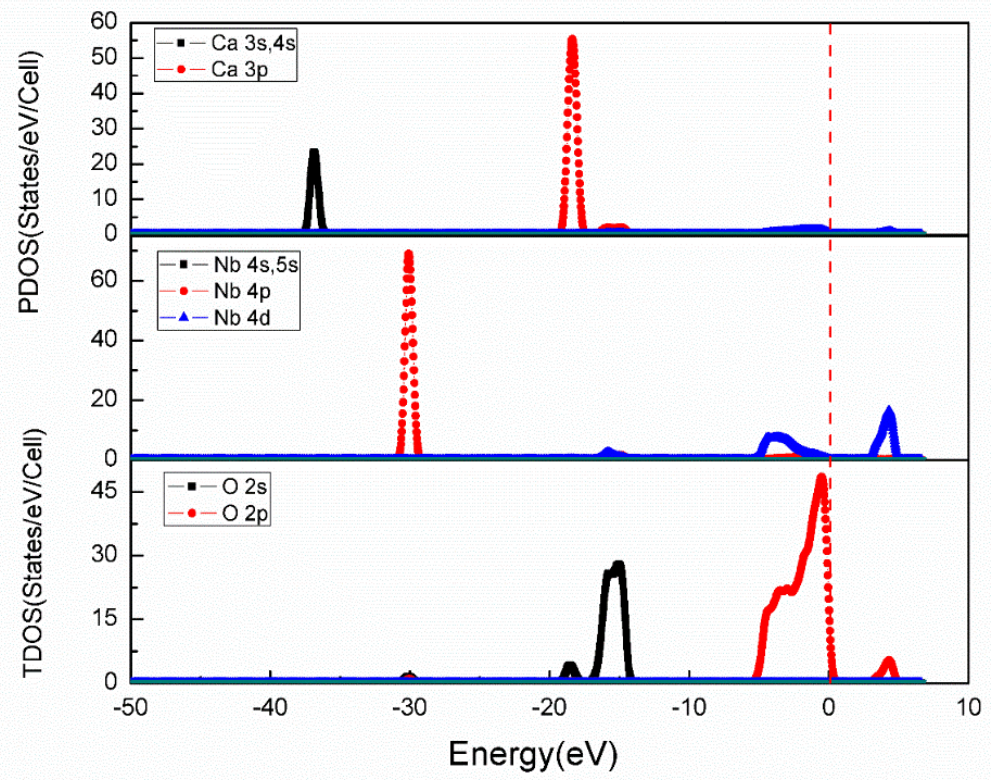

Fig. 5

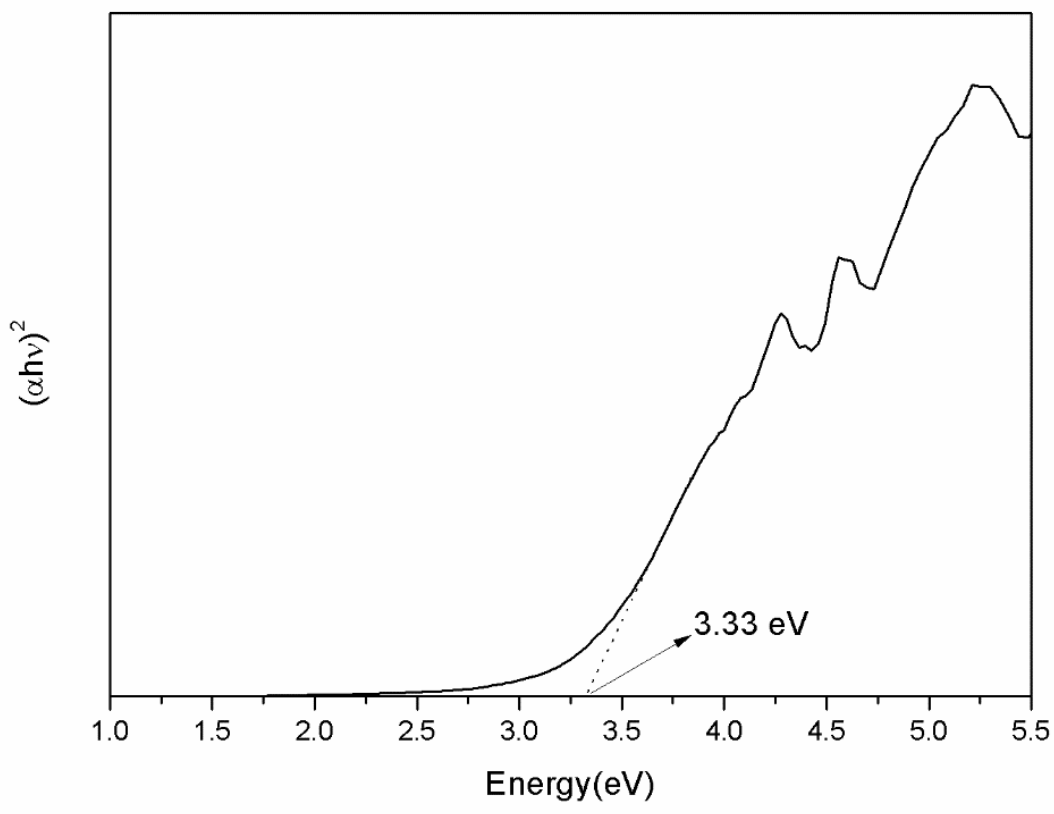

Fig. 6 


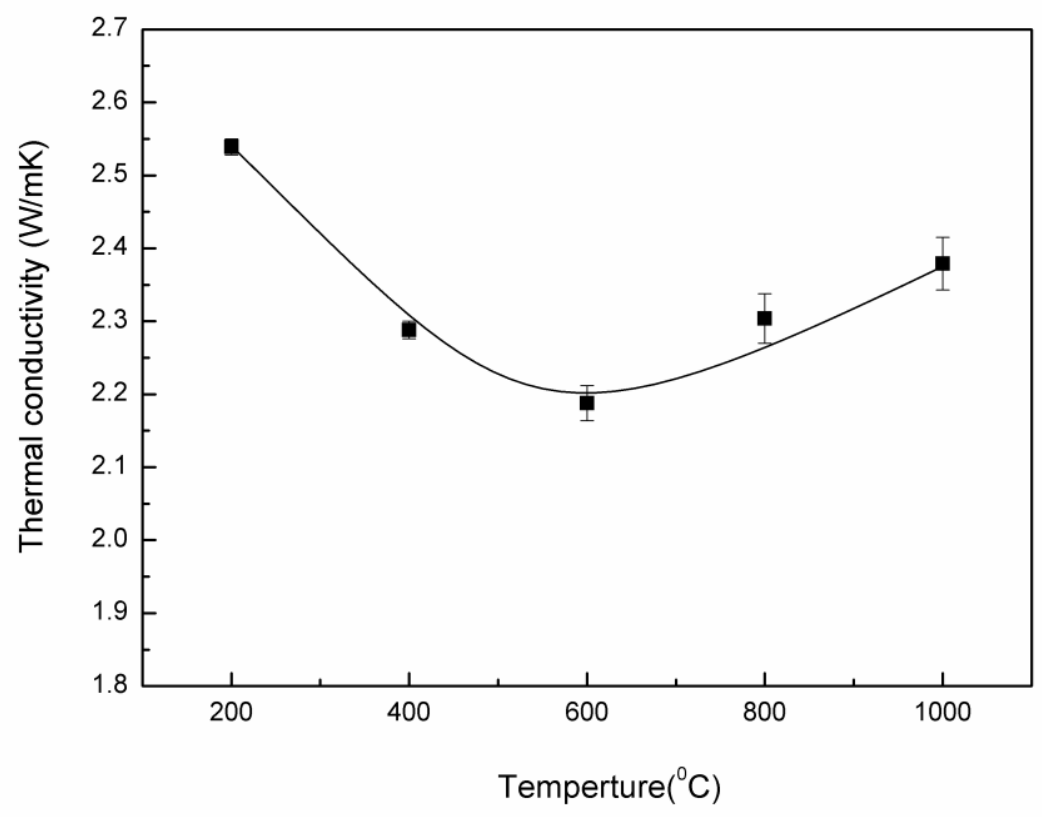

Fig. 7

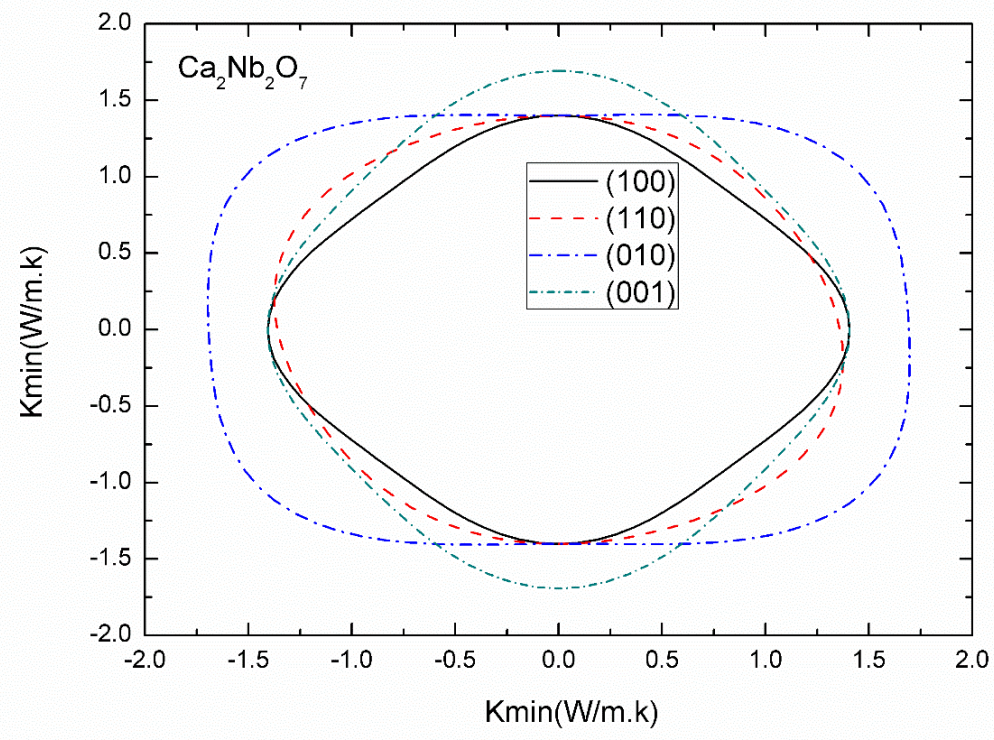

Fig. 8

Table 1 Lattice parameters, volume, cohesive energy and formation enthalpy of monoclinic $\mathrm{Ca}_{2} \mathrm{Nb}_{2} \mathrm{O}_{7}$ crystal

\begin{tabular}{ccccccccc}
\hline Method & $a(\AA)$ & $b(\AA)$ & $c(\AA)$ & $c / a$ & $\gamma\left({ }^{0}\right)$ & $V\left(\AA^{3}\right)$ & $E c(e V / a t o m)$ & $\Delta H(k J / m o l)$ \\
\hline $\mathrm{Cal}^{\mathrm{a}}(\mathrm{LDA})$ & 7.60 & 13.27 & 5.40 & 0.711 & 98.3 & 539.1 & -9.09 & -4656.61 \\
$\mathrm{Cal}^{\mathrm{a}(\mathrm{GGA})}$ & 7.73 & 13.65 & 5.53 & 0.715 & 98.3 & 578.3 & -8.76 & -4114.27 \\
\hline
\end{tabular}




\begin{tabular}{|c|c|c|c|c|c|c|c|c|}
\hline $\operatorname{Exp}^{a}$ & 7.67 & 13.44 & 5.53 & 0.721 & 98.2 & 564.6 & - & - \\
\hline $\operatorname{Exp}^{\mathrm{b}}$ & 7.70 & 13.39 & 5.50 & 0.714 & 98.3 & 560.8 & - & - \\
\hline $\operatorname{Exp}^{c}$ & 7.69 & 13.38 & 5.50 & 0.715 & 98.3 & 560.8 & - & - \\
\hline
\end{tabular}

${ }^{a}$ This work ; ${ }^{b}$ PDF\#74-0390. ${ }^{\mathrm{R}}$ ef.[26]

Table 2 The calculated independent elastic constants of $\mathrm{Ca}_{2} \mathrm{Nb}_{2} \mathrm{O}_{7}$ crystals (in $\mathrm{GPa}$ ).

$\begin{array}{llllllllllllllll}\text { Compound } & \text { Space } & C_{11} & C_{22} & C_{33} & C_{44} & C_{55} & C_{66} & C_{12} & C_{13} & C_{15} & C_{23} & C_{25} & C_{35} & C_{46}\end{array}$ $\begin{array}{lllllllllllllll}\mathrm{Ca}_{2} \mathrm{Nb}_{2} \mathrm{O}_{7} & P 2 & 296.2 & 214.3 & 220.7 & 55.3 & 94 . & 64.7 & 62.6 & 79.3 & -3.7 & 80.8 & -1.3 & -0.7 & -8.1\end{array}$

$\mathrm{Ca}_{2} \mathrm{Nb}_{2} \mathrm{O}_{7} \quad F d-3 M \quad 281.4 \quad 117.2 \quad-\quad 107.1$

$\mathrm{CaO} \quad F M-3 M \quad 77.5 \quad 28.3 \quad-\quad 77.9$

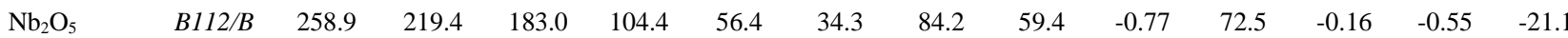

Table 3 The Bulk Modulus $B$, Shear Modulus $G$, Young's Modulus $E$, and Vickers micro-hardness $H v$ of $\mathrm{Ca}_{2} \mathrm{Nb}_{2} \mathrm{O}_{7}$ crystals combining with $\mathrm{CaO}$ and $\mathrm{Nb}_{2} \mathrm{O}_{5}$ crystals (in $\mathrm{GPa}$ ). Note that $G / B$ and $A^{U}$ are dimensionless parameters.

\begin{tabular}{|c|c|c|c|c|c|c|c|c|c|c|c|c|c|}
\hline $\mathrm{Ca}_{2} \mathrm{Nb}_{2} \mathrm{O}_{7}$ & Cal & $P 2_{1}$ & 130.7 & 128.8 & 129.8 & 76.8 & 71.9 & 74.3 & 187.3 & 10.9 & 0.26 & 0.57 & 0.35 \\
\hline $\mathrm{Ca}_{2} \mathrm{Nb}_{2} \mathrm{O}_{7}$ & $\mathrm{Cal}$ & $F d-3 M$ & 165.2 & 165.2 & 165.2 & 95.1 & 96.5 & 95.8 & 222.3 & 14.1 & 0.27 & 0.58 & 0.07 \\
\hline $\mathrm{CaO}$ & $\mathrm{Cal}$ & $\begin{array}{c}F M-3 \\
M\end{array}$ & 44.7 & 44.7 & 44.7 & 56.6 & 41.7 & 49.2 & 62.4 & 7.2 & 0.27 & 1.1 & 0.35 \\
\hline
\end{tabular}

Table 4 The anisotropy of Young's modulus and Poisson's ratio of $\mathrm{Ca}_{2} \mathrm{Nb}_{2} \mathrm{O}_{7}$ crystals combining with $\mathrm{CaO}$ and $\mathrm{Nb}_{2} \mathrm{O}_{5}$ crystals. 


\begin{tabular}{|c|c|c|c|c|c|c|c|c|c|c|}
\hline \multirow{2}{*}{ Compound } & \multirow{2}{*}{$\begin{array}{l}\text { Space } \\
\text { Group }\end{array}$} & \multicolumn{3}{|c|}{$E$} & \multicolumn{6}{|c|}{$\sigma$} \\
\hline & & $E_{x}$ & $E_{y}$ & $E_{z}$ & $\sigma_{x y}$ & $\sigma_{x z}$ & $\sigma_{y x}$ & $\sigma_{y z}$ & $\sigma_{z x}$ & $\sigma_{z y}$ \\
\hline $\mathrm{Ca}_{2} \mathrm{Nb}_{2} \mathrm{O}_{7}$ & $P 2{ }_{1}$ & 261.5 & 180.5 & 179.1 & 0.18 & 0.29 & 0.13 & 0.32 & 0.20 & 0.32 \\
\hline $\mathrm{Ca}_{2} \mathrm{Nb}_{2} \mathrm{O}_{7}$ & $F d-3 M$ & 222.3 & 222.3 & 222.3 & 0.27 & 0.27 & 0.27 & 0.27 & 0.27 & 0.27 \\
\hline $\mathrm{CaO}$ & $F M-3 M$ & 62.4 & 62.4 & 62.4 & 0.27 & 0.27 & 0.27 & 0.27 & 0.27 & 0.27 \\
\hline $\mathrm{Nb}_{2} \mathrm{O}_{5}$ & $B 112 / B$ & 220.3 & 175.2 & 154.6 & 0.31 & 0.19 & 0.25 & 0.31 & 0.13 & 0.27 \\
\hline
\end{tabular}

Table 5 The calculated sound velocities in three principal axes of monoclinic $\mathrm{Ca}_{2} \mathrm{Nb}_{2} \mathrm{O}_{7}$ crystal.

\begin{tabular}{|c|c|c|c|c|c|c|c|c|c|}
\hline \multirow{2}{*}{ Compound } & \multicolumn{3}{|c|}{ [100] } & \multicolumn{3}{|c|}{ [010] } & \multicolumn{3}{|c|}{$[001]$} \\
\hline & $v_{t}$ & $v_{+}$ & $v$ & $v_{l}$ & $v_{t+}$ & $v_{t-}$ & $v_{t}$ & $v_{+}$ & $v$ \\
\hline $\mathrm{Ca}_{2} \mathrm{Nb}_{2} \mathrm{O}_{7}$ & 3729.2 & 7976.4 & 4495.3 & 6784.0 & 3861.2 & 3297.3 & 3445.8 & 6884.7 & 4496.8 \\
\hline $\begin{array}{r}\text { Table } \\
\text { monoclini }\end{array}$ & $\begin{array}{l}\text { The cal } \\
\mathrm{Ca}_{2} \mathrm{Nb}_{2} \mathrm{C}\end{array}$ & $\begin{array}{l}\text { ulated sc } \\
\text { 7. The ex }\end{array}$ & $\begin{array}{l}\text { ound veloc } \\
\text { perimenta }\end{array}$ & $\begin{array}{l}\text { ties, Deb } \\
\text { sound ve } \\
\text { mean so }\end{array}$ & $\begin{array}{l}\text { e temper } \\
\text { locities as } \\
\text { and veloc }\end{array}$ & $\begin{array}{l}\text { ature, a } \\
\text { e obtail } \\
\text { ity. }\end{array}$ & $\begin{array}{l}\text { d minimum ther } \\
\text { ed by ultrasonic }\end{array}$ & $\begin{array}{l}\text { condu } \\
\text { hod an }\end{array}$ & $\begin{array}{l}\text { vity of } \\
v_{m} \text { is the }\end{array}$ \\
\hline Compound & Method & $v_{l}(\mathrm{~m} / \mathrm{s})$ & $v_{t}(\mathrm{~m} / \mathrm{s})$ & $v_{m}(m / s)$ & $\Theta_{D}(K)$ & & $\kappa_{\min }($ Clarke $)\left(W \cdot m^{-1} \cdot K^{-1}\right)$ & $\kappa_{\min (}$ & l) $\left(W \cdot m^{-1} \cdot K^{-1}\right)$ \\
\hline \multirow[t]{2}{*}{$\mathrm{Ca}_{2} \mathrm{Nb}_{2} \mathrm{O}_{7}$} & $\mathrm{Cal}$ & 7011.3 & 3995.5 & 4440.8 & 521.4 & & 1.43 & \multicolumn{2}{|c|}{1.57} \\
\hline & Exp & 7200.0 & 3950.0 & 4400.0 & \multicolumn{2}{|l|}{ - } & - & \multicolumn{2}{|c|}{ - } \\
\hline
\end{tabular}

\section{Figure Legends:}

Fig. 1. The crystals structure of monoclinic $\mathrm{Ca}_{2} \mathrm{Nb}_{2} \mathrm{O}_{7}$ compound with space group $\mathrm{P} 2{ }_{1}$.

Fig. 2. SEM micrograph of polished and etched section of monoclinic $\mathrm{Ca}_{2} \mathrm{Nb}_{2} \mathrm{O}_{7}$ specimen.

Fig. 3. X-ray diffraction patterns of monoclinic $\mathrm{Ca}_{2} \mathrm{Nb}_{2} \mathrm{O}_{7}$ specimen.

Fig. 4. The calculated band structures of monoclinic $\mathrm{Ca}_{2} \mathrm{Nb}_{2} \mathrm{O}_{7}$ compound. The dashed line is the Fermi energy.

Fig. 5. The calculated angular projected density of states (PDOS) and total density of states (TDOS) of monoclinic $\mathrm{Ca}_{2} \mathrm{Nb}_{2} \mathrm{O}_{7}$ compound within LDA, The dashed line is the Fermi energy.

Fig. 6. Band gap of monoclinic $\mathrm{Ca}_{2} \mathrm{Nb}_{2} \mathrm{O}_{7}$ compound by experimental results. The intercept of extrapolated straight line is the 
corresponding fitted band gap.

Fig. 7. Thermal conductivity of the monoclinic $\mathrm{Ca}_{2} \mathrm{Nb}_{2} \mathrm{O}_{7}$ specimen.

Fig. 8. Planar projections of minimum thermal conductivities of $\mathrm{Ca}_{2} \mathrm{Nb}_{2} \mathrm{O}_{7}$ compounds at (001), (010), (100), and (110) planes, respectively. 